\title{
LA EVALUACIÓN DE LOS EXÁMENES DE TRADUCCIÓN EN LA ENSEÑANZA SUPERIOR
}

\author{
Víctor Manuel Borrero Zapata IJuan Pablo Larreta Zulategui \\ Universidad de Sevilla
}

\begin{abstract}
This paper deals with the relationship of several topics in translation teaching, such as the assessment of student output, to the academic and professional worlds of translation. The authors claim that the character of the academical setting demands specific assessment criteria, somewhat different from those used in professional environments to evaluate translation quality.
\end{abstract}

\section{MARCO TEÓRICO DE LA EVALUACIÓN DE LA TRADUCCIÓN EN EL ÁMBITO ACADÉMICO}

\subsection{Ideas básicas subyacentes al modelo de evaluación}

En el ámbito académico de los estudios de traducción, enjuiciar los trabajos realizados por el estudiante con el objeto de obtener una calificación es una tarea compleja y a menudo conflictiva. Por ello, creemos que es imprescindible, al elaborar la programación de una asignatura de práctica de la traducción, establecer una serie de criterios de evaluación claros (que necesariamente poseerán un valor didáctico-terapéutico) que compartan junto a la enunciación de los objetivos del curso la tarea de guiar al estudiante en su aprendizaje. De lo dicho, se desprende que partimos de la base de que unos criterios preestablecidos son mucho más aconsejables que la simple autoridad del profesor. Aunque aquí no vayamos a presentar una teoría cerrada, sí defenderemos una serie de ideas que lleven a construirla; y, sobre todo, que ayuden a que la labor de evaluación se base en criterios objetivos establecidos a priori. De hecho, ante eventuales pruebas, el estudiante deberá conocer no sólo los criterios de evaluación, sino también los conceptos lingüísticotraductológicos en los que se fundan. Huelga decir que nos centramos en la evaluación de traducciones como actividad dirigida al aprendizaje de la práctica de la traducción, y no como recurso pedagógico en la enseñanza de lenguas extranjeras, cuestión también extremadamente interesante que, no obstante, excede los límites temáticos de este artículo.

En este camino hacia la fijación de unos criterios objetivos de evaluación, es preciso que abordemos temas que atañen no ya al producto final de la actividad traductora, sino a esta misma actividad y todo lo que le concierne, ya que es todo el proceso, y no sólo su resultado, lo que pensamos debe medirse en una evaluación académica. Esta exigencia teórica es de difícil aplicación práctica y, sin embargo, por su importancia, demanda una investigación empírica exhaustiva y una reflexión teórica profunda por parte del docente.

Al hilo de esta última idea surge un último motivo relevante en la exposición e ilación de los conceptos de este artículo: las posibles divergencias de la evaluación académica 
respecto al ejercicio profesional. Creemos que es relevante tener presentes en todo momento aquellas cuestiones en las que la evaluación académica deba coincidir o no con lo que acontece en el mercado profesional. Anticipándonos, dado que una meta inexcusable de los estudios de traducción es la capacitación profesional, nuestra opinión es que no pueden perderse de vista las exigencias del mercado de trabajo en los años de formación. Sin embargo, cabe introducir la duda de que siempre y en todo momento el enjuiciamiento en ambos ámbitos deba ser coincidente, por lo que su análisis en el único ámbito que compete al docente debe observar conceptos ajenos al ejercicio profesional. En cualquier caso, aunque la evaluación académica no se rija exclusivamente conforme a directrices del mercado, no nos cabe duda de que será de una ayuda inestimable para el futuro traductor, en el ámbito profesional, ser conscientes de cuáles son los mecanismos de corrección de una traducción puede servir para ejercitar la autocrítica y también como herramienta de defensa del propio trabajo ante eventualidades (reclamaciones del cliente, litigios jurídicos) del mercado de trabajo.

\subsection{El marco traductológico en la concepción del error de traducción y de su evaluación}

Para poder exponer nuestros puntos de vista acerca de la objetivización de los criterios de evaluación de una traducción, del peso en la evaluación tanto del proceso como del resultado de la traducción y de las afinidades y divergencias que debe mostrar la evaluación académica respecto a las circunstancias que determinan la valoración del traductor y su trabajo en el mundo profesional, tenemos que apoyarnos en los anclajes teóricos de dos clásicos de la Ciencia de la Traducción moderna. El primero de ellos es la Teoría de la Función del TM (Skopostheorie) de Reiß/Vermeer (1984), en tanto en cuanto tiene en cuenta en sus disquisiciones actividades que desde una perspectiva traductológica clásica tal vez no fueran consideradas traducciones, pero que pertenecen a la actividad profesional del traductor actual. Por ello, independientemente de la exactitud de esta teoría', deben ser enseñadas y, en consecuencia, evaluadas en los estudios de traducción. En relación a esta teoría y junto a los conceptos de estos autores, no podemos dejar de hacer mención del papel que puede o debe desempeñar el TO en la evaluación de una traducción (cuestión en la que, como se verá, nos alejamos de la teoría mencionada). El segundo soporte teórico es

\footnotetext{
' Reiß/Vermeer (1984) intentan, por así decirlo, conjugar teóricamente todas las circunstancias que concurren o pueden concurrir en el proceso de la traducción. El problema surge cuando pretenden aglutinar todos estos factores bajo el concepto de la función del TM. De ahí se deriva una curiosa postración a un segundo plano del TO. J. Albrecht (Albrecht 1998) realiza una crítica precisa, subrayando consecuencias graves, especialmente en el campo de la traducción literaria. Al respecto, este autor afirma: "Dies alles führt zu schwerwiegenden Konsequenzen auf dem Gebiet der literarischen Übersetzung. (...). Man hat bei der Lektüre skopostheoretischer Arbeiten den Eindruck, als werde Funktionskonstanz zwischen Ausgangs- und Zieltext eher als Ausnahme denn als Regel angesehen. Damit läßt sich meines Erachtens eine Übersetzung nicht mehr von einer Bearbeitung unterscheiden. (...) Es mu $\beta$ erkennbar sein, da $\beta$ die Funktion des übersetzten Texts nicht ausschlie $\beta$ lich im Hinblick auf textexterne Faktoren gewählt, sondern wenigstens teilweise aus Charakteristika des Originals abgeleitet wurde." (Albrecht 1998: 259). La misma K. Reiß parece alejarse con el tiempo de esta teoría (véase K. Reiß, "Der Ausgangstext - das sine qua non der Übersetzung", TextConText, 1990, 31-39.)
} 
la adaptación didáctica del encargo de traducción de Christiane Nord. En consonancia con la Teoría de la Función del TM, esta autora introduce en sus consideraciones relativas a la didáctica de la traducción cuestiones inherentes a la actividad profesional, y resalta, en nuestra opinión, unos parámetros que resultarán muy útiles para la labor evaluadora.

\subsection{La Teoría de la Función del TM y el valor del TO en la evaluación}

En lo que a la Teoría de la Función del TM respecta, aunque no vayamos a detenernos en ella en profundidad, sí quisiéramos hacer algunos comentarios relativos a la definición general de traducción que dan sus autores, para centrarnos en los aspectos que más nos interesan en relación con la evaluación.

Rei $\beta /$ Vermeer (1984) definen de la siguiente manera la actividad traductora:

(1) La base teórica se compone de tres afirmaciones:

(1) Una traducción se realiza en función de la meta que persigue. (...)

(2) Traducir consiste en ofrecer una información determinada a una cultura receptora y a su lengua a partir de una información procedente de la cultura emisora y de su lengua.

(3) La oferta de información de una traducción se representa como transferencia que refleja la información de partida. Ese reflejo no es unívocamente convertible ${ }^{2}$.

Acerca del primer punto, central en la teoría, y en el que se afirma que el proceso de traducción y las decisiones que va adoptando el traductor deben depender del objetivo que se persiga con el TM, de lo cual se desprende que esta teoría sólo contempla y define la actividad traductora dentro de un marco contextual comunicativo, y no como mera confrontación del traductor con un texto y sus cualidades inmanentes, sólo queremos reseñar, si bien en esta definición no se explicita, que esta teoría considera que las funciones del TO у TM pueden diferir (sobre la consideración que nos merece este postulado desde un punto de vista teórico, véase nota a pie 1).

El segundo punto contiene, pensamos, dos postulados, uno explícito y otro implícito (aunque suficientemente expuesto y desarrollado por los autores en otras partes de su obra). En primer lugar, se recuerda explícitamente que el acto de traducción no es una

2 "Die Theoriebasis besteht aus drei Behauptungen. (...).

(1) Translation is eine Funktion ihres Skopos.

(2) Translation ist ein Informationsangebot in einer Zielkultur und deren Sprache über ein Informationsangebot aus einer Ausgangskultur und deren Sprache.

(3) Das Informationsangebot einer Translation wird als abbildender Transfer eines Ausgangsangebots dargestellt. Die Abbildung ist nicht eindeutig umkehrbar." (Reiß/Vermeer 1984: 105). 
confrontación puramente lingüística, sino lingüística y cultural. Más relevante para la evaluación nos parece el axioma implícito, pues se alude a la independencia del proceso de traducción respecto al TO: de modo muy genérico, la información contenida en él ("ein Informationsangebot aus einer Ausgangskultur und deren Sprache") sólo es un punto de partida muy maleable mediante el cual el traductor acaba ofreciendo una información en la cultura receptora ("ein Informationsangebot in einer Zielkultur und deren Sprache"). Atendiendo a este postulado, la inclusión del TO dentro del proceso de evaluación se convierte en una cuestión controvertida ${ }^{3}$.

Si la información del TO es maleable; si la función del TM en la cultura receptora puede diferir de la función del TO en la cultura de partida; si una traducción no se mide (o no sólo) por la competencia lingüística contrastiva (lo que supondría que corregir una traducción es únicamente comparar las equivalencias gramaticales y semánticas de los TO y TM en un contexto de emisión, digamos, neutro), habrá que plantearse si, en tal caso, es necesario tener en cuenta el TO para evaluar una traducción; y, si la respuesta es afirmativa, en qué medida debe tenerse en cuenta. Según nuestro parecer, el peso del TO (y de su contexto de emisión) a la hora de evaluar un trabajo de traducción o adaptación podrá ser variable pero, en cualquier caso, su concurso será necesario en la evaluación académica. La idea, defendible desde la posición de la Teoría de la Función del TM, de que el texto de partida pueda no tener valor al evaluar una traducción en el ámbito académico no nos parece muy adecuada. Incluso aceptando la posibilidad de que el TM pueda no mantener la constante de la función respecto al TO, necesitamos no perder de vista este último para cotejar el trabajo de manipulación realizado por el traductor. En esta cuestión, ciertamente, mundo académico y mundo profesional no se dan la mano. En este último, la importancia del TO es muy relativa. Así, Peter A. Schmitt (1997) afirma:

\begin{abstract}
¿Debe ser la utilidad del TM para el promotor de la traducción la única medida para valorarla, o debe tenerse en cuenta también al TO? Dado que aquí estamos tratando sólo de textos especializados (textos pragmáticos), su utilidad para la finalidad perseguida es el criterio fundamental. Los textos pragmáticos no suelen traducirse habitualmente para saber cómo ha sido formulado el TM, sino para solucionarle un problema de comunicación al promotor que paga. Este necesita la traducción para algo determinado, y el TO sólo es una ayuda. Dependiendo del tipo de texto, el TO desempeña una papel distinto en el proceso de valoración de la utilidad del $\mathrm{TM}^{4}$.
\end{abstract}

\footnotetext{
${ }^{3}$ Respecto al tercer punto, no hay nada que nos llame la atención en lo que a la evaluación respecta. En cualquier caso, su formulación nos resulta ligeramente críptica: si bien los autores reconocen que la oferta de información resultante del proceso de traducción es una transferencia que refleja la información de partida, se afirma que ese reflejo no puede ser invertido unívocamente (dada la maleabilidad del TO y la posibilidad del traductor de manipular de modo diverso esa información). Nos queda la duda de saber qué entienden los autores por "reflejo", aunque en esta obra de Rei $\beta /$ Vermeer (1984) no parece complicado hallar palabras en las que su significado se ve modificado respecto al significado codificado, usualizado y compartido por la comunidad de hablantes.
}

4 "Soll die ZT-Brauchbarkeit für den Auftraggeber alleiniger Bewertungsmaßstab sein (...) oder spielt der AT eine Rolle? Da es hier ausschließich um Fachtexte (Gebrauchstexte) geht, ist deren Brauchbarkeit für den angegebenen Zweck das entscheidende Kriterium. Gebrauchstexte werden normalerweise nicht dafür übersetzt, um zu erfahren, wie der AT formuliert ist, sondern um für einen zahlenden Auftraggeber ein Kommunikationsproblem zu lösen - 
Esta cita de Schmitt (1997) es ilustrativa de la diferencia entre el mundo profesional y el académico. En el primero de ellos, a quien encarga una traducción no le interesan los aspectos filológicos ni los aspectos procesuales de la traducción; le interesa que el producto por el que paga sea correcto y sirva a sus fines. Por ello, la mayor o menor afinidad con el TO, en general, sobre todo si los textos, como aquí se afirma, son pragmáticos, le será indiferente. Un profesor, sin embargo, debe valorar retrospectivamente el trabajo del estudiante: no debe interesarle sólo el resultado final de ese trabajo sino también, como afirmábamos al inicio, el proceso seguido para realizarlo, pues ese proceso es igualmente un proceso de aprendizaje y en él despliega el estudiante sus conocimientos y aptitudes. Ello implica valorar el proceso de traducción y las decisiones que éste haya ido tomando, teniendo en cuenta la formulación de la pregunta del examen. Al respecto, pensamos que el estudiante podrá o deberá explicar cómo o por qué se ha inclinado por una solución determinada en pasajes de la traducción que indique el profesor previamente; e incluso podrá tener derecho a defender a posteriori soluciones que resulten controvertidas para quien valora el trabajo, esto es, el profesor. Para ello deberá haber sido formado en conceptos básicos de la pragmática, de la Teoría de la Comunicación y de la lingüística textual.

\subsubsection{Análisis textual y encargo de traducción en Nord}

Según lo visto hasta ahora, hay que encontrar un modo de evaluar objetivamente, teniendo en cuenta el proceso de traducción y desligando cuando sea necesario la valoración académica de la profesional, sin olvidar, no obstante, que la formación del estudiante debe dirigirse a lograr que se desenvuelva en el mundo profesional (sin olvidar la motivación adicional que supone simular o hacer asemejar la actividad en el aula con la de este mundo). Así, en exámenes finales (no así en pruebas conducentes a controlar una capacidad específica), la "simulación" en el examen de la actividad real es importante, hecho que no implica necesariamente que se vaya a juzgar con los mismos parámetros. Por ello, la formulación de una pregunta en un examen de traducción (sobre todo de textos pragmáticos), se basará en los conceptos teóricos expuestos: en el TM que deberá redactar el traductor habrá que tener en cuenta cuál es la función textual, y para ello el traductor posee un mayor grado de libertad respecto al TO que lo permitido en la traductología clásica, aunque puede verse constreñido por diversas circunstancias textuales y extratextuales. En la formulación de la pregunta, que deberá recoger todo lo aprendido sobre la competencia traductora, no podrá incluirse únicamente un escueto "Traduce ...", sino "Teniendo en cuenta las circunstancias ... traduce ...". De esta manera, el estudiante estará obligado a sopesar todas esas circunstancias textuales y extratextuales que deben influir en su labor. Para ello, deberá conocer un método de análisis, que igualmente se 
convertirá en medida objetiva de la evaluación. El profesor medirá, valorando en qué medida el estudiante ha tomado sus decisiones respetando las circunstancias concretas de su trabajo, qué decisiones son correctas y cuáles no. Muy interesante en ese sentido nos parece el esquema propuesto por Nord (1991), el segundo de los pilares teóricos a los que hacíamos alusión, para una aplicación didáctica del análisis del texto que debe ser traducido y del encargo de dicha traducción. Exponemos un ejemplo suyo simplificado:

Supongamos que el traductor recibe el encargo de reformular del español al alemán un prospecto turístico de la ciudad de Sagunto de parte del ayuntamiento de dicha ciudad. El texto, de 1977, que versa acerca de la historia de la ciudad y de sus monumentos, debe volver a ser editado con igual formato en el verano de 1986 para ser repartido en los centros de información de la ciudad, ya que se ha producido un incremento del turismo procedente de Alemania. Con el prospecto se quiere hacer la ciudad más atractiva al turista, manteniendo toda la información del original. Antes de ponerse al trabajo, el traductor debería analizar todos los factores textuales y extratextuales que pueden incidir en su trabajo, para tomar así las decisiones oportunas y establecer sus procedimientos de traducción. Reproducimos parcialmente el cuadro de Nord (1991: 163) en el que se realiza ese análisis y se asocia a los diversos problemas de traducción y posibles procedimientos para resolverlos:

\begin{tabular}{|c|c|c|c|}
\hline & TO & $\begin{array}{c}\text { Problemas y } \\
\text { procedimientos de } \\
\text { traducción }\end{array}$ & TM \\
\hline \multicolumn{4}{|c|}{ A. FACTORES EXTRATEXTUALES } \\
\hline Emisor & $\begin{array}{l}\text { Ayuntamiento de } \\
\text { Sagunto }\end{array}$ & & $\begin{array}{l}\text { Ayuntamiento de } \\
\text { Sagunto }\end{array}$ \\
\hline Receptor & $\begin{array}{c}\text { Turistas } \\
\text { hispanoparlantes: } \\
\text { conocimientos de } \\
\text { historia y geografía } \\
\text { españolas. }\end{array}$ & $\begin{array}{l}\text { Equilibrar los } \\
\text { conocimientos } \\
\text { enciclopédicos. }\end{array}$ & $\begin{array}{c}\text { Turistas } \\
\text { germanoparlantes: } \\
\text { mínimos } \\
\text { conocimientos, pero } \\
\text { motivados. }\end{array}$ \\
\hline Medio & $\begin{array}{c}\text { Prospecto } \\
\text { desplegable, fotos a } \\
\text { color, tamaño de } \\
\text { letra mínimo. }\end{array}$ & $\begin{array}{l}\text { Limitaciones de } \\
\text { espacio. } \\
\text { Textos a pie de foto. }\end{array}$ & $\begin{array}{c}\text { La edición no puede } \\
\text { experimentar } \\
\text { cambios. }\end{array}$ \\
\hline Lugar & $\begin{array}{l}\text { Recepción en } \\
\text { Sagunto. }\end{array}$ & $\begin{array}{l}\text { Utilidad como mapa } \\
\text { y callejero. } \\
\text { Nombres propios en } \\
\text { español. }\end{array}$ & $\begin{array}{l}\text { Recepción en } \\
\text { Sagunto. }\end{array}$ \\
\hline
\end{tabular}




\begin{tabular}{|c|c|c|c|}
\hline Tiempo & $\begin{array}{l}\text { Producido en } 1977 . \\
\text { Emitido desde } \\
\text { entonces. }\end{array}$ & $\begin{array}{l}\text { Comprobar la } \\
\text { actualidad de las } \\
\text { informaciones. }\end{array}$ & $\begin{array}{c}\text { Producido en el } \\
\text { verano de } 1986 . \\
\text { Emitido desde } \\
\text { entonces. }\end{array}$ \\
\hline Función textual & $\begin{array}{l}\text { Información y } \\
\text { propaganda. }\end{array}$ & $\begin{array}{c}\text { Jerarquía funcional: } \\
\text { información sobre } \\
\text { propaganda. }\end{array}$ & $\begin{array}{c}\text { Sobre todo } \\
\text { información, dado } \\
\text { que el turista ya está } \\
\text { allí. }\end{array}$ \\
\hline \multicolumn{4}{|c|}{ B. FACTORES INMANENTES DEL TEXTO } \\
\hline Léxico & $\begin{array}{c}\text { Español-castellano, } \\
\text { connotativo, } \\
\text { emotivo y } \\
\text { propagandístico. }\end{array}$ & $\begin{array}{c}\text { Adecuar a las } \\
\text { convenciones } \\
\text { estilísticas y } \\
\text { funcionales del TM. }\end{array}$ & $\begin{array}{c}\text { Alemán de la R.F.A. } \\
\text { Más informativo que } \\
\text { propagandístico. }\end{array}$ \\
\hline Sintaxis & $\begin{array}{l}\text { Abundante } \\
\text { subordinación, } \\
\text { aposiciones, } \\
\text { enumeraciones, etc. }\end{array}$ & $\begin{array}{l}\text { Subdividir los } \\
\text { periodos largos. }\end{array}$ & $\begin{array}{l}\text { Estructuras más } \\
\text { sencillas para } \\
\text { adecuar a la función } \\
\text { textual. }\end{array}$ \\
\hline \multicolumn{4}{|c|}{ C. EFECTO } \\
\hline Efecto & $\begin{array}{c}\text { Animar a los turistas } \\
\text { a visitar la ciudad y } \\
\text { a recomendarla }\end{array}$ & & $\begin{array}{l}\text { Los turistas deben } \\
\text { sentirse bien, } \\
\text { conocer y orientarse } \\
\text { en la ciudad la } \\
\text { ciudad, } \\
\text { recomendarla. }\end{array}$ \\
\hline
\end{tabular}

Todos estos parámetros deben, en definitiva, ser empleados por el estudiante en su tarea y, consecuentemente, tenidos en cuenta por el profesor en la evaluación. Llegamos así teóricamente a la objetivización de la evaluación, a la ampliación de la evaluación del resultado al proceso y a la diferenciación, cuando es necesario, de los mundos académicos y profesional en este ámbito (siempre se tendrá al TO como punto de apoyo). Con ello, sin embargo, seguimos inmersos en un razonamiento teórico en el que necesitamos proseguir reflexionando sobre dos cuestiones capitales: ¿qué se entiende por error de traducción en este contexto? y ¿pueden y deben ser jerarquizados los errores de traducción? A ello le dedicamos el segundo epígrafe de este artículo.

\section{EL ERROR DE TRADUCCIÓN EN EL ÁMBITO ACADÉMICO}

La detección y valoración del error tiene una función principal como unidad de medida para la evaluación de un texto traducido. Sin embargo, el valor que se ha dado habitualmente a esta medida ha venido variando sustancialmente, sobre todo en las últimas décadas. 
Por error de traducción se ha entendido tradicionalmente un "desvío de una norma, de una convención o de un sistema de reglas" (Nord, 1991: 194). Como se colige inmediatamente del ejemplo anterior, la norma infringida ignoraba, en esta definición, aspectos de la situación comunicativa en la periferia del material evaluado que eran distintos del propio texto, como la intención, la función, la motivación, el espacio, el tiempo, el contexto de generación, las expectativas del destinatario o el propio perfil del sujeto agente de la traducción.

La consideración actual de estos aspectos enriquece el análisis de la reconstrucción del significado y, consecuentemente, también perfecciona el método de valoración crítica. Sin embargo, al establecerse esta nueva combinatoria de opciones, este complejo de relaciones entre factores intra- y extratextuales, entre mensaje y emisor, mensaje y receptor, mensaje y código, mensaje y contexto, etc., la tarea de localización y valoración de errores ha ganado en nuevas dificultades, sobre todo a la hora de establecer jerarquías de valor entre las opciones de este nuevo catálogo que compiten con el propio significado inmanente del texto.

En cualquier caso, la función de la unidad del error en la evaluación, aunque distinta ahora, se sigue revelando útil, imprescindible para el diagnóstico de problemas y para la enunciación de su correspondiente terapia. El ámbito de aplicación de esta praxis es variada: la tradicional crítica de la traducción, en crisis después de esplendorosos siglos de polémicas, que por su propia naturaleza persigue objetos más teóricos y generales; la traducción profesional, donde un método con estas pretensiones es una herramienta provechosa para la autocorrección o para la corrección/supervisión, según una rutina sistemática, de textos ajenos por encargo; y la didáctica de la traducción, ya sea como medio para un fin último, el aprendizaje de una lengua, o como fin en sí mismo, para la capacitación profesional del traductor. Obedeciendo al objetivo que nos hemos marcado desde un principio para el presente artículo, este último es el ámbito en el que nos vamos a centrar a continuación.

\subsection{Parámetros generales para la evaluación del error de traducción}

La elaboración de un método que permita localizar errores en la traducción y, al mismo tiempo, asignarles un valor, es una tarea compleja si se pretende realizar desde un cierto interés pragmático. La creación de un sistema que sirva para medir el nivel de acierto o de adquisición de destrezas a partir de una traducción tropieza con una dificultad principal: la de resolver las tensiones entre elementos que coexisten dentro del proceso de la traducción, asignándoles una función dentro de él.

Nos referimos a tres pares especialmente activos en el proceso de evaluación: el par de los aspectos objetivos y subjetivos susceptibles de ser evaluados; los elementos intra- y extratextuales, y la cuestión del carácter abierto, esto es, adaptado a cada situación, o cerrado del sistema de valoración.

La distinción entre aspectos objetivos y subjetivos es sólo propia de los elementos externos, extratextuales, del objeto de evaluación. El texto, entendido en un sentido 
estricto, no admite esta diferenciación. No debe confundirse con una evaluación objetiva o subjetiva, porque no se refiere al tipo de enfoque de análisis, sino a la naturaleza de lo evaluado, es decir, a la diagnosis de errores detectables en el propio perfil del traductor (sujeto), o en la interpretación/expresión de la información que procede de los elementos que condicionan la traducción desde las fronteras externas al texto (objeto). El método debe equilibrar las proporciones de valor que se asigna, respectivamente, a las fuerzas objetivas y subjetivas que participan en el resultado final, en el Translat.

Estos elementos externos permiten explicar la función comunicativa que debe cumplir el mensaje traducido, habitualmente explícitas en las instrucciones del encargo, y amplían la tradicional definición del significado, restringida a la propia inmanencia del texto. Intervienen en el método declarando su prevalencia sobre los elementos intratextuales (como el contenido o la temática). Sin embargo, estos últimos tienen un lugar especial en la valoración académica, porque su dominio cumple un papel fundamental en el itinerario de formación del traductor.

El tercer par corresponde a la oposición entre el carácter abierto (relativo) o cerrado (absoluto) del sistema de valoración. El mayor o menor grado de flexibilidad (la apertura) en la jerarquía de criterios valorativos no viene dado necesariamente por la mayor o menor actualidad del método, más bien ésta se manifiesta, como ya ha venido subrayándose anteriormente, así se apliquen los criterios en el curso de evaluaciones profesionales o académicas.

Estas últimas, las académicas, admiten una menor flexibilidad de adaptación de los criterios valorativos a los condicionantes externos simulados del proceso evaluado, probablemente porque estos deben mantenerse estables durante el transcurso de la formación del futuro traductor. También es así, probablemente, porque, en el marco de ese mismo itinerario de formación, el formador no puede permitirse renunciar a exigir a sus alumnos el dominio de facultades no necesariamente imprescindibles para el cumplimiento del encargo en cuestión.

\subsection{Procedimiento de localización y valoración de errores en el ámbito académico- profesional}

Una vez revisados estos parámetros fundamentales, llegamos al punto principal: ¿cómo se valora un error? El procedimiento para reconocer errores en el ámbito académicoprofesional puede articularse en tres momentos principales antes de la aplicación final de los criterios de valuación: la definición del marco teórico y metodológico general en el que se va a desarrollar la evaluación; la determinación del objetivo de la evaluación, dicho de otra manera, la selección de los elementos que van a participar en ella, así como, en relación directa con éste, de la cota mínima exigible para un resultado satisfactorio; y la jerarquización de los criterios de la evaluación académica con sus correspondientes factores modificadores de la corrección. 


\subsubsection{Marco teórico}

La definición del marco general de la evaluación es el primer paso y probablemente el fundamental en cualquier proceso. Tradicionalmente, este marco ha sido bastante restrictivo y se ha reducido a la fidelidad del texto traducido respecto al original. Hoy en día, la evaluación de textos traducidos, ya sea en el ámbito académico o en el profesional, se sitúa en la comprobación de la correspondencia entre la función dada al TO y el TM, objeto de la evaluación. Bajo el planteamiento teórico descrito más arriba, el marco teóricometodológico se concreta en la comprobación en ambos textos de la equivalencia de las funciones comunicativas elegidas para ellos y notificadas en el encargo, concepto que Nord (1991: 164) denomina Faktorenkonstanz. En él, el factor contenido es uno más de los elementos que no debe dejar de observarse al lado de otros factores, entre los que también adquieren una importancia capital, por ejemplo, otros factores como la intención, la motivación, o el efecto que debe tener el texto más allá del dominio del propio autor en la situación comunicativa del destinatario.

\subsubsection{Objetivo de la evaluación: las condiciones del encargo}

Una vez definido el marco, procede su expresión a través de un objetivo de evaluación. Este objetivo, tanto en el caso de las traducciones profesionales como en el enunciado de una prueba académica, contiene las instrucciones definidas dentro de los parámetros de la evaluación. Es decir, selecciona qué cuestiones deben aparecer resueltas en el texto final para que éste cumpla solventemente las funciones comunicativas más o menos explícitas del texto original. Son lo que se denomina, en terminología alemana. W-Fragen, las cuales, también en el ámbito de la traducción, se refieren a qué (qué no), sobre qué, quién, para qué, a quién, a través de qué medio, dónde, cuándo, por qué dar a conocer un texto con qué función (Nord, 1991), en qué orden, con qué palabras, con qué recursos no verbales, con qué unidades frásticas, en qué tono, con qué intención, a partir de qué motivación o con qué efecto.

Estas cuestiones aparecen de modo más o menos manifiesto en el TO, en su contexto de realización comunicativa. No obstante, es habitual que todas o una buena parte de ella ya vengan contenidas en la virtualidad del encargo.

La respuesta a estas cuestiones, planteadas por el propio evaluador, informa de una manera precisa sobre qué condiciones o instrucciones del encargo (tanto si se trata de una traducción profesional real como si es simulada en una prueba) han sido satisfactoriamente resueltas en el TM. La información obtenida por este procedimiento tiene mucho valor, aunque no colma completamente lo que esperamos de una evaluación global. Esto es así por dos razones muy poderosas: primero, porque los incumplimientos que desvela este examen no están aún valorados. Ello quiere decir que, teóricamente, todos los errores aparecen a los ojos del evaluador como del mismo valor mientras no se establezca un rasero que los jerarquice por su grado de incumplimiento de acuerdo con las condiciones del encargo. 
En segundo lugar, y relacionado directamente con lo anterior, los datos resultantes de esta primera inspección no permiten concluir por sí mismos si el TM, en su conjunto, supera las exigencias mínimas para que se pueda considerar equivalente o correspondiente a la función asignada al original.

Una vez localizados los errores, se imponen dos cuestiones fundamentales. En primer lugar, el evaluador se pregunta si la traducción ha vencido, en lo fundamental, las dificultades planteadas por el TO, o dicho de otro modo, se cuestiona si la traducción es mínimamente correcta. A continuación, si la respuesta es afirmativa, quiere conocer en qué grado ha cumplido las condiciones establecidas por este TO.

\subsubsection{El límite de admisibilidad}

Para dar respuesta a la primera cuestión, parece lógico que se tome como referencia para medir el nivel de cumplimiento del TM, el propio límite de admisibilidad (Toleranzgrenze, según Schmitt, 1997: 308-312) contenido en el propio encargo o en las instrucciones implícitas en el propio texto. Este rasero refleja su correspondencia con el marco funcionalista previsto en la definición del objetivo de evaluación. Según este planteamiento, como ya se ha referido antes, un texto no debe sólo trasladar contenidos de una lengua a otra, debe cumplir también una serie de funciones, y éstas deben reflejarse de modo equivalente -en la medida de lo posible de la manera más literal- en el TM.

Asimismo, estas funciones, como así recoge la Skopostheorie, pueden ser en cada caso variables, dependientes de las circunstancias concretas del encargo. Por tanto, este criterio eminentemente pragmático será extremadamente receptivo a las exigencias del mercado: el modo de comprobar el grado de cumplimiento de un texto respecto a las exigencias de su cliente, que es en definitiva el destinatario o consumidor final (Hönig/Kußmaul, 1984).

Pese a que, en lo fundamental, la evaluación de la traducción académica con vocación profesional toma este patrón como referencia principal, el proceso de valoración en un marco académico debe atenuar la gravedad de este requisito único con la introducción de otras referencias evaluadoras, correspondientes a otras facetas importantes en el itinerario de formación del traductor, como el dominio de las normas gramaticales de la propia lengua, la capacidad interpretativa del sujeto, o, de modo más general, su grado de progresión en un contexto dado de formación, aunque éstas no afecten en lo fundamental de manera inmediata al carácter de admisible o no admisible del TM (véase infra 2.3.5.2). Por esta razón, se impone al evaluador la elaboración de una tabla de referencia abierta o relativa que contemple una jerarquización definida de los distintos tipos de errores, al tiempo que se muestre flexible a los condicionantes que impone el contexto comunicativo. 


\subsubsection{Tipología de errores}

La tipologización de errores de acuerdo con criterios profesionales o comerciales tiende habitualmente a la simplificación ${ }^{5}$. Reduce el ámbito de evaluación a las cuestiones fundamentales que pueden afectar al éxito o al fracaso del trabajo encargado desde el punto de vista de la satisfacción del cliente. Esas cuestiones suelen concentrarse, por orden de importancia, en la funcionalidad del resultado (función, tipo de texto, perfil del destinatario, etc.), donde no se admiten errores; y en un nivel secundario, en el sentido (congruencia), en la corrección (sintáctica, ortográfica, etc.) y en el estilo, donde errores de esta naturaleza se suelen admitir en una medida moderada, siempre que las instrucciones del encargo (como, por ejemplo, en el caso de un texto literario) no prescriba el cuidado de estos aspectos entre las tareas fundamentales.

La evaluación académica, por el contrario, exige una categorización más amplia y matizada, que dé respuesta a la demanda de información del formador respecto a la progresión de las distintas facultades del alumno que concurren en la actividad traductora. En este tipo de examen, el TO cumple un papel primordial. No sólo interesará al evaluador que el TM responda a la función asignada, dependiendo del ejercicio, al TO. También querrá conocer el grado de dominio de las técnicas elementales para traducir, para transferir a otro código las funciones inmanentes del TO. Así, la observación de las características textuales cobra un valor sustancial en el proceso de evaluación académica. En este sentido, hay que distinguir entre la valoración eminentemente prospectiva de la evaluación profesional (la que pone su punto de mira en el TM y en su capacidad para cumplir con la encomienda del cliente) y la valoración retrospectiva propia de la evaluación académica para la capacitación profesional (la que persigue, como misión principal, encontrar correspondencias entre la función inmanente del TO con su expresión en el TM).

Esta categorización demanda la organización del complejo de ítems de evaluación desplegado por estas diferencias de planteamiento, la cual se ha realizado en el presente de acuerdo con la combinación de los parámetros objetividad / subjetividad e intratextualidad / extratextualidad comentados más arriba:

1. Elementos externos:
1.1.
1.2 .
Objetivos: función, tipología textual, intención, horizonte de expectativas, lugar, tiempo, medio y motivo.
Subjetivos: la capacidad interpretativa del traductor, el perfil del sujeto traductor (Persönlichkeitsstruktur des Übersetzers, en términos de Reiß), el procedimiento empleado.

\footnotetext{
${ }^{5}$ Schmitt (1997: 308-310) cita el manual de corrección de IBM. Este establece tres niveles con el correspondiente límite de recurrencia de errores en cada nivel. La gravedad extrema corresponde a los fachliche Fehler (errores profesionales o de especialidad). Le sigue la gravedad moderada de los errores terminológicos (terminologische Fehler) para concluir con los errores tolerables hasta cierta medida en el apartado de los sprachliche Fehler (errores lingüísticos). Schmitt apostilla con su propia categorización abierta de errores: contra las condiciones del encargo, contra los datos contenidos en el original, contra la corrección política y el sentido común, contra la lógica o las leyes de la naturaleza y contra la norma lingüística.
} 
2. Elementos internos: sentido (contenido, coherencia textual), corrección (política, gramatical, ortográfica, tipográfica, terminológica, de la presentación formal) y estilo (adecuación y uniformidad de registro, congruencia)

Destaca en este esquema la presencia de una categoría de errores, entre los de orden externo o extratextual, que evalúa elementos constitutivos de la "personalidad profesional" del traductor. Esta categoría es tratada por Reiss (1984: 109-115) y se refiere a aquellas anomalías, detectables no necesariamente en un único texto y a través del incumplimiento puntual de funciones o de normas. Antes bien, estas son localizables en el perfil profesional del traductor, que se manifiesta habitualmente a través de sus decisiones interpretativas. Según Reiss, no sólo las decisiones concretas, sino también el tenor general de las decisiones tomadas por el traductor, analizadas en su conjunto, aportan información fundamental sobre su fisonomía como traductor, sobre su modo de entender la actividad traductora, que puede ser "erróneo" o "anómalo" y afectar a sus futuras decisiones 6 .

A pesar del evidente beneficio pedagógico de una valoración de este tipo, debe reconocerse la dificultad metodológica que entraña su aplicación de una manera sistemática sobre un grupo real de estudiantes de traducción. Difícilmente un solo texto ofrece de una manera diáfana el esquema de interpretación de su autor y, en el caso -improbable- de que pudiera reconocerse efectivamente, resulta problemático establecer la ponderación que debe tener este tipo de "deficiencia" en relación con el resto de las facetas evaluadas. Por este motivo, parece recomendable que este tipo de información del sujeto, subjetiva (recordemos, por el carácter de su fuente, no por el tipo de tratamiento que se le da), sea administrada por el evaluador como el resultado de una evaluación no calificativa, al objeto de ofrecer orientación al alumno sobre el tipo de especialización que más le conviene.

Por otra parte, del esquema se deduce que la valoración de errores "no funcionales" tiene una importancia mayor en la evaluación académica que en la profesional. Los elementos intratextuales muestran la capacidad de comprensión, interpretación y expresión del alumno, así como su nivel de conocimiento de ciertas "normas" (gramaticales, de diferenciación de registros, de estilo, del discurso políticamente correcto, culturales, de lógica, de retórica, ortográficas, etc.), nociones que pueden resultar fundamentales para la progresión del alumno en la resolución de problemas de traducción con un nivel exigente de calidad.

Pese a ello, no debe olvidarse que la enseñanza de la traducción profesional debe preparar para el conocimiento de las normas particulares del mercado, las cuales, como ya ha sido referido antes, hacen prevalecer como criterio principal el grado de eficacia medido por el nivel de satisfacción del cliente. Estas normas pueden, póngase el caso, privilegiar el criterio que corresponde al plazo de entrega sobre el cuidado formal final del producto, o

\footnotetext{
${ }^{6}$ Reiss abunda en este aspecto y describe, a partir de un modelo proporcionado por Eduard Spranger, la tipología o "caracteriología" de estructuras de pensamiento aptas para la ciencia y, en este caso, para la traducción. Se trata de: el "hombre teórico"(objetivo y desapasionado, para traducciones técnicas y filosóficas), el "hombre económico" (pragmático, para traducciones audiomediales) y el "hombre estético" (sensible, para traducciones literarias), principalmente.
} 
incluso sobre la corrección gramatical, a priori más importante. Luego la formación en la traducción no debe ignorar estas normas, antes bien debe instruir sobre su importancia, otorgándole a los errores "funcionales" un lugar prevalente en el proceso de evaluación.

Un ejemplo ilustra esta idea. Procede de la virtualidad de nuestro entorno cotidiano. En la traducción a varios idiomas de unas instrucciones de manejo de un aparato de climatización son detectables un par de anomalías de relieve?

a. Bedienen Sie die Schalter niemals mit nassen Händen. Sie können einen Stromschlag bekommen

b. Wenn Flüssigkeit aus den AlkalinAkkus auf Ihre Haut oder Ihre Kleidung gelangt, diese gründlich mit klarem Wasser abwaschen. Wenn Flüssigkeit aus den Alkalin-Akkus in Ihre Augen gelangt, diese gründlich mit klarem Wasser auswaschen und sofort einen Arzt konsultieren
No maneje interruptores con las manos húmedas. Puede provocar una descarga eléctrica

Si el líquido de las pilas alcalinas entra en contacto con su piel o ropa, límpielo con agua. Si el líquido de las pilas alcalinas entra en contacto con sus ojos, lávelos abundantemente con agua limpia y consulte a su médico.

En el primero de los casos, la instrucción fundamental en el TO es respetada en lo fundamental en el TM. El cliente verá salvaguardada su integridad física si atiende a esta indicación, esto es, si no opera con el aparato con las manos humedecidas. El error se produce en la traducción de las consecuencias de la acción. El usuario no es señalado en el texto original como sujeto, sino como objeto de la acción, es decir, ante todo aquel, quien advierte del peligro, pone énfasis en que será éste, el usuario potencial, quien reciba la descarga eléctrica si se contraviene la instrucción principal.

En el último ejemplo, el error más importante consiste en la omisión en el TM de un adverbio que intensifica temporalmente la acción del verbo que dicta la instrucción fundamental ("sofort"). No se trata tanto de que el usuario afectado por el accidente visite a su médico, sino de que acuda inmediatamente al servicio de urgencias médicas en el mismo momento en que sus ojos se hayan visto dañados por su contacto con el líquido de las pilas alcalinas.

En ambos casos, los dos errores de traducción afectan de manera directa a la semántica del texto. Practicando una evaluación restrictiva, inmanente al texto, ambos errores quedan adscritos a la misma escala valorativa, la que concierne al sentido, entendido éste como elemento interno. Sin embargo, desde un punto de vista pragmático, atendiendo a su contexto de realización, es decir, a los condicionantes del encargo, el primero de ellos

\footnotetext{
${ }^{7}$ Manual de instrucciones para los modelos MCFH-A12/18/24WV y MCFZ-A18/24WV de Mitsubishi Electric, p. 14 y 47 .
} 
apenas incide sobre la función, mientras que el último la contraviene de manera diametral. La primera traducción puede ser admisible desde un punto de vista profesional, e igualmente, si bien penalizada por su déficit en competencia traductora, en una evaluación académica. La última incumple la encomienda básica del encargo.

\subsubsection{Los factores modificadores}

Tanto en la evaluación académica como en la profesional, independientemente del peso que se conceda en la valoración a los distintos tipos de error, existen una serie de factores que pueden incidir en la valoración final de la traducción, atenuando o agravando la incidencia del error sobre el resultado de la evaluación. Así, suponiendo incluso que, al caso, el error estilístico de una traducción, de acuerdo con las características de un encargo, tuviera un valor menor respecto a otras categorías de error, resulta evidente que su incidencia sobre el resultado global de la valoración debe modularse teniendo en consideración que se trate, dentro de su categoría, de una falta leve o grave, que estas incidencias sean frecuentes en la superficie del texto y que su aparición sea puntualmente localizable; o que, por el contrario, se extienda a lo largo de toda la redacción como una madeja que resulta difícil desentrañar y, desde luego, recomponer.

Nos referimos a los factores de gravedad, recurrencia y corregibilidad de los errores. No nos podemos detener aquí en la definición de error grave o leve en cada una de las diferentes categorías. Existen errores ortográficos más permisibles que otros, y existen licencias expresivas que se pueden tolerar frente a auténticos atentados contra el estilo. De igual manera, existen errores que perjudican la valoración de la traducción por la recurrencia con que aparecen. Así, la valoración de un error contingente recibirá una penalización menor que un error sistemático.

Por último, debe tenerse en cuenta, además de la gravedad intrínseca y de la recurrencia, el grado de dificultad con que esos errores pueden ser restituidos. Un error, $a$ priori menos grave, puede perjudicar ya no tanto el objeto general de la traducción, sino su posibilidad de ser corregido a posteriori.

\section{CONClusiones}

El artículo ha querido llamar la atención sobre tres aspectos principales que, para sus autores, deben tomarse en cuenta a la hora de evaluar traducciones en el ámbito académico con vocación profesional:

Primeramente, subraya la necesidad de distinguir entre los criterios y los métodos que deben regir las evaluaciones académicas y profesionales respectivamente. Teniendo ambas en común la consideración del contexto comunicativo (las condiciones del encargo, ya sean virtuales o simuladas) y el límite de admisibilidad del TT, la evaluación académica establece niveles de error que contemplan otras facetas indispensables en su itinerario formativo, como el dominio de los códigos gramatical y ortográfico, y que no son consideradas indefectiblemente por la evaluación profesional. 
En segundo lugar, con una propuesta de jerarquización de errores y la enunciación de sus correspondientes factores modificadores, incide en la importancia que tiene la elaboración de criterios para la evaluación desarrollados a priori que auxilien la labor del corrector y que ofrezcan referencias al estudiante para el autoaprendizaje.

Por último, destaca la conveniencia de que estos criterios evaluadores mantengan, no obstante lo anterior, un carácter flexible, abierto y relativo que les permita adaptarse en cada caso al tipo de texto y a las condiciones del encargo.

\section{REFERENCIAS BIBLIOGRÁFICAS}

ALBRECHT, J., Literarische Übersetzung: Geschichte, Theorie, kulturelle Wirkung, Darmstadt, Wissenschaftliche Buchgesellschaft, 1998.

HÖNIG, G. / KUßMAUL, P. Strategie der Übersetzung: ein Lehr- und Arbeitsbuch. Tübingen: G. Narr, 1984.

KAUTZ, U., Handbuch Didaktik des Übersetzens und Dolmetschens. München: Iudicium, Goethe Institut, 2002.

NORD, CH., Textanalyse und Übersetzen: theoretische Grundlagen, Methode und didaktische Anwendungen einer übersetzungsrelevanten Textanalyse, $2^{\mathrm{a}}$ ed..., Heidelberg, Groos, 1991.

REI $\beta$, K., "Der Ausgangstext - das sine qua non der Übersetzung”, TextConText, 1990, 3139.

REI $\beta$, K. / VERMEER, H., Grundlagen einer allgemeinen Translationstheorie, Tübingen, Niemeyer, 1984.

SCHMITT, P. A., "Evaluierung von Fachübersetzungen", Modelle der Translation: Festschrift für Albrecht Neubert. Frankfurt a.M., Vervuert, 1997. 